\title{
Interesse dos discentes da medicina veterinária pela área de alimentos
}

\author{
Interest of veterinary medicine students in the food area \\ Interés de los estudiantes de medicina veterinaria en el área de la alimentación
}

Recebido: 01/12/2021 | Revisado: 09/12/2021 | Aceito: 14/12/2021 | Publicado: 21/12/2021

\author{
Pâmela Strapasson \\ ORCID: https://orcid.org/0000-0002-9231-4802 \\ Universidade Federal da Fronteira Sul, Brasil \\ E-mail: pamelastrapasson@ hotmail.com \\ Sonia Mara Fontes dos Santos \\ ORCID: https://orcid.org/0000-0002-3056-9850 \\ Universidade Federal da Fronteira Sul, Brasil \\ E-mail: soniamarafontes31@gmail.com \\ Karina Ramirez Starikoff \\ ORCID: https://orcid.org/0000-0001-8378-9972 \\ Universidade Federal da Fronteira Sul, Brasil \\ E-mail: karina.starikoff@uffs.edu.br
}

\begin{abstract}
Resumo
Os estudantes de medicina veterinária recebem uma educação multidisciplinar para que tenham uma formação generalista, a fim de estarem aptos para atender às necessidades exigidas pela sociedade. Entretanto, a maior parte dos alunos ingressam no curso com a intenção de atuarem nas clínicas, desconhecendo outras áreas. O objetivo desta pesquisa foi analisar a afinidade pela área de alimentos dos discentes do curso de medicina veterinária da Universidade Federal da Fronteira Sul - Campus Realeza. A pesquisa foi realizada por meio da aplicação de questionário de forma online. Participaram da pesquisa 257 graduandos e egressos. O perfil de participantes foi majoritariamente de mulheres $(72,4 \%)$, jovens entre 20 a 25 anos $(60,31 \%)$ e de origem da região Sul $(77,8 \%)$. E $91,1 \%$ dos participantes afirmaram escolher o curso por identificação e afinidade, inicialmente às áreas de clínica ou cirurgia de pequenos e grandes animais (35,4\% e $28,8 \%$ respectivamente). Porém $45,1 \%$ mudaram de opinião. Dos participantes, $96,9 \%$ consomem produtos de origem animal e 73,9\% tinham conhecimento que o médico veterinário poderia atuar na área de alimentos, e um crescimento linear nas respostas do primeiro ao quinto ano sobre trabalhar nesta área. Assim faz-se necessário a realização de trabalhos educativos e informativos a fim de conscientizar a comunidade e incentivar os estudantes a interagir e participar com todas as áreas possíveis da veterinária, para que estes compreendam o vasto campo de atuação.
\end{abstract}

Palavras-chave: Ensino superior; Medicina veterinária preventiva; Inspeção de produtos de origem animal.

\begin{abstract}
Veterinary medicine students receive a multidisciplinary education to have generalist training, and to be able to meet the needs demanded by society. However, most students enter the course with the intention of working in clinics, not knowing other areas. The objective of this research was to analyze the affinity for the food area of students from the veterinary medicine course at Federal University of Fronteira Sul - Campus Realeza. The research was carried out through the application of an online questionnaire, 257 undergraduates and graduates participated in the research. The profile of participants was mostly women (72.4\%), young people aged between 20 and 25 years $(60.31 \%)$ and from the South region (77.8\%). And $91.1 \%$ of participants said they chose the course by identification and affinity, initially to the areas of clinic or surgery of small and large animals (35.4\% and $28.8 \%$ respectively). However, $45.1 \%$ changed their opinions. Of the participants, $96.9 \%$ consumed animal products and $73.9 \%$ were aware that the veterinarian could work in the food area, and a linear growth in the responses from the first to the fifth year about working in this area. Thus, it is necessary to carry out educational and informative work in order to raise awareness in the community and encourage students to interact and participate with all possible areas of veterinary medicine, so that they understand the vast field of action.
\end{abstract}

Keywords: University education; Preventive veterinary medicine; Inspection of products of animal origin.

\section{Resumen}

Los estudiantes de Medicina Veterinaria reciben una formación multidisciplinar para que tengan una formación generalista, con el fin de poder cubrir las necesidades que demanda la sociedad. Sin embargo, la mayoría de los estudiantes ingresan al curso con la intención de trabajar en clínicas, sin conocer otras áreas. El objetivo de esta investigación fue analizar la afinidad por el área alimentaria de estudiantes de la carrera de Medicina Veterinaria de la Universidad Federal de Fronteira Sul - Campus Realeza. La investigación se llevó a cabo mediante la aplicación de un 
cuestionario en línea. Y 257 estudiantes de pregrado y posgrado participaron en la investigación. El perfil de los participantes fue mayoritariamente mujeres (72,4\%), jóvenes de entre 20 a 25 años $(60,31 \%)$ y de la región Sur (77,8\%). El 91,1\% de los participantes dijo que eligió el curso por identificación y afinidad, inicialmente en las áreas de clínica o cirugía para animales pequeños y grandes (35,4\% y 28,8\% respectivamente). Sin embargo, el $45,1 \%$ cambió de opinión. De los participantes, $96,9 \%$ consumen productos de origen animal y 73,9\% son conscientes de que el veterinario podría trabajar en el área de alimentación, y un crecimiento lineal en las respuestas del primero al quinto año sobre trabajar en esta área. Por ello, es necesario realizar una orientación educativa e informativa con el fin de sensibilizar a la comunidad y animar a los estudiantes a interactuar y participar con todas las áreas posibles de la medicina veterinaria, para que comprendan el amplio campo de actuación.

Palabras clave: Educación universitaria; Medicina veterinaria preventiva; Inspección de productos de origen animal.

\section{Introdução}

A graduação em medicina veterinária visa a formação de profissionais generalistas, com capacidade e conhecimento para atuar nos mais diversos ramos, já que existem mais de 80 áreas especializadas. As grandes áreas abordam a cirurgia e a clínica de grandes ou pequenos animais, a produção animal, a inspeção de alimentos e a saúde pública. O médico veterinário pode trabalhar como pesquisador, responsável técnico, docente, perito criminal nessas diferentes áreas. Para isso, o meio acadêmico deve incentivar que os discentes realizem atividades extracurriculares e complementares, para adquirir experiência e se preparar para as possibilidades da carreira. E também para que se sintam preparados para enfrentar desafios, solucionar problemas, liderar grupos, fazer ciência e ajudar a comunidade (Andrade Júnior et al., 2019).

O médico veterinário geralmente é apresentado como "aquele que cuida das doenças dos animais", que executa a prática hegemonicamente remediativa na clínica e cirurgia. Contudo, a Organização Mundial da Saúde Animal (OIE) demanda do médico veterinário muito além da responsabilidade enquanto formado, requer o conhecimento em um nível de competência adequado às demandas da sociedade, apontando questões de grande relevância social, como a produção de alimentos com a utilização de métodos sustentáveis, proteção ao meio ambiente e profilaxia das novas zoonoses com potencial epidêmico e que tenha o acompanhamento de necessidades da sociedade atual que antecipe o futuro, sem que haja afastamento das origens de saúde pública (Pfuetzenreiter \& Zylbersztajn, 2008; Taffarel, 2014; Torres \& Chirelli, 2019).

Para o setor agropecuário, uma das áreas com maior contribuição econômica é a inspeção de produtos de origem animal, sendo uma atividade essencial. Atualmente o Brasil é o segundo maior produtor e o primeiro maior exportador de carne de frango. Na suinocultura, lidera o quarto lugar como produtor e exportador (CONAB, 2019). Já a pecuária de corte tem grande influência sobre o Produto Interno Bruto (PIB) brasileiro, em 2019 representou 8,5\% do PIB total (Cobucci, 2017; ABIEC, 2020).

Os altos níveis tecnológicos utilizados pelas agroindústrias brasileiras fazem com que o país permaneça em destaque no cenário mundial. Com produtos de qualidade e preços competitivos, o Brasil é um dos mais importantes produtores e exportadores de mercadorias de origem animal, representando cerca de um quinto da carne produzida, comercializada e distribuída no mundo, e para que se mantenha competitivo no mercado e com qualidade sanitária atestada pelos órgãos regulatórios de inspeção nacionais, os preceitos e adequações às exigências internacionais devem manter-se em evolução (Costa et al., 2015; Magioli, 2017; CONAB, 2019)

Assim, também é de competência privativa do médico veterinário o exercício da inspeção e da fiscalização sob o ponto-de-vista sanitário, higiênico e tecnológico de estabelecimentos de todos os produtos de origem animal nos locais de produção, manipulação, armazenagem e comercialização (Brasil, 1968).

A visão superficial da profissão interfere na relevância e no reconhecimento social, induzindo os anseios dos estudantes de veterinária que ingressam no curso com o interesse nas clínicas e não cogitam outras especialidades como as áreas de inspeção de produtos de origem animal ou saúde pública. Além disso, a formação dependendo da instituição ainda é muito focada nas clínicas e o contato dos estudantes com as áreas voltadas à saúde pública se dá apenas no final do curso, 
assim, muitos acabam saindo com uma formação fragmentada e despreparados para tais demandas, que são de extrema importância e muito promissores dentro de órgãos públicos nas mais diferentes esferas governamentais (Pfuetzenreiter \& Zylbersztajn, 2008; Svoboda \& Javouki, 2011).

Assim, o objetivo desta pesquisa foi analisar o perfil e a afinidade pela área de alimentos de origem animal dos discentes do curso de medicina veterinária da Universidade Federal da Fronteira Sul (UFFS) - Campus Realeza/Paraná.

\section{Metodologia}

Este trabalho foi submetido e aprovado pelo Comitê de Ética em Pesquisa (CEP) da UFFS (parecer de número 59380516.9.0000.5564). A coleta de dados iniciou-se após a aprovação do CEP por meio da aplicação de questionário de forma online (Google Forms), e também após permissão dos voluntários por meio do Termo de Consentimento Livre e Esclarecido (TCLE) digital. O contato com os participantes foi realizado por e-mail cadastrado no sistema institucional.

A pesquisa foi realizada no período de agosto de 2020 a abril de 2021. E trata-se de uma pesquisa aplicada, descritiva, com base em uma abordagem quali-quantitativa.

A amostra, definida por conveniência, foi composta até que se obteve porcentagem mínima de $40 \%$ de participação dos alunos registrados no sistema institucional. Como critérios de inclusão na pesquisa foram utilizadas as respostas dos alunos matriculados em todas as fases que estavam cursando medicina veterinária na instituição e os formados no mesmo curso desde a criação (2010) até abril de 2021. Foram excluídos os alunos de outros cursos de graduação e os desistentes do curso de medicina veterinária.

O questionário foi composto por 3 seções:

1. Questões sobre perfil discente: idade (com categorias de menor de 20 anos; entre 20 a 25; entre 26 a 30; e maior que 30); sexo (com categoria feminino, masculino ou outro); etapa da graduação: do primeiro ao quinto ano e formado; Cidade e Estado antes de entrar na graduação; se a residência se localizava em zona rural, urbana ou mista; que tipo de ensino médio cursaram: tradicional ou técnico; se já eram formados em outra graduação de nível superior; se tentaram ingressar em outro curso superior;

2. Questões sobre a escolha do curso: qual motivo da escolha pelo curso de medicina veterinária; se havia tentado ingressar em outro curso e qual; qual a área de interesse inicial (Clínica ou cirurgia de grandes animais, Clínica ou cirurgia de pequenos animais, Produção animal, Saúde Pública, Animais silvestres, Inspeção de Produtos de Origem Animal ou outra), se havia mudado de opinião e para qual área; para os formados: qual área você fez o estágio curricular obrigatório; e após a formatura, onde você trabalhou (área e por quanto tempo).

3. Questões sobre a área de alimentos: se consumia produtos de origem animal (leite, lácteos, ovos, mel, carnes e derivados); se não, o motivo; e se sabia, ao ingressar no curso de medicina veterinária, que o veterinário poderia atuar na inspeção e vigilância de estabelecimentos como supermercados, frigoríficos e até indústrias com alimentos de origem animal, atuando na fiscalização e vistoria de suas dependências.

Para análise dos resultados foi utilizado o programa Microsoft Excel® 2011 para verificar as porcentagens, as linhas de tendência e a confecção dos gráficos. Os dados foram analisados através de estatística descritiva.

\section{Resultados e Discussão}

Participaram desta pesquisa um total de 257 estudantes e ex-alunos do curso de medicina veterinária da UFFS, o que representa $40,72 \%$ dos alunos registrados.

A grade curricular de medicina veterinária na UFFS é composta por 11 semestres, o que equivale a um período de 5 anos e meio de graduação. No primeiro ano os componentes curriculares estão voltados às ciências sociais e humanas, com 
introdução aos conhecimentos básicos. No segundo ano há mais componentes básicos para compreensão das ciências veterinárias. A partir do terceiro ano começam as matérias específicas, com as ciências de clínica e cirurgia, produção animal e zootecnia, que continuam no quarto ano. No quinto e último ano estão as ciências de saúde pública e medicina preventiva, inspeção e tecnologia de produtos de origem animal. Sendo o último semestre destinado ao estágio obrigatório (UFFS, 2010).

\subsection{Perfil dos estudantes}

A maioria dos participantes desta pesquisa eram jovens entre 20 a 25 anos (60,31\% das respostas), 14,8\% tinham menos de 20 anos, 19,46\% entre 26 e 30 anos e 5,45\% acima de 30 anos. Em relação aos participantes graduandos do $2^{\circ}$ ao $5^{\circ}$ ano a predominância desta faixa etária foi de 70,06\% (117/161). Já no $1^{\circ}$ ano, 60\% (21/35) eram menores de 20 anos. O que demonstra que a maioria dos estudantes tende a sair do ensino médio e ingressar no ensino superior.

Em pesquisa com 33 estudantes do $3^{\circ}$ ano de curso Técnico de Nível Médio Integrado ao Ensino Médio do Instituto Federal de Educação, Ciência e Tecnologia de São Paulo, 54,8\% (17/33) pensavam em prestar vestibular e seguir no ensino superior, sendo que $29 \%$ (9/33) queriam fazer curso pré-vestibular e o restante (5/33) começar a trabalhar. A necessidade por iniciar uma graduação está, por vezes, diretamente inter relacionada com a construção sociocultural do sujeito. Muitas vezes sem ter sua identidade formada e convicção do curso que deseja, o jovem é pressionado a escolher. Entretanto, no futuro podem ocorrer questionamentos e frustrações sobre sua escolha, o que pode culminar na desistência por falta de conhecimento sobre a área escolhida (Cardoso et al., 2019).

O perfil etário em pesquisa com estudantes de medicina veterinária do Sudeste foi de 73,92\% (913/1.235) para jovens entre 17 a 21 anos e 11,18\% (138/1.235) para jovens de 22 e 24 anos. O pesquisador ressalta a importância da maturidade para escolha da profissão e aponta que nos Estados Unidos os estudantes do primeiro ano em medicina veterinária têm em média 24 anos, e tendem a apresentar maior maturidade, experiência e confiança para cursarem aquilo que almejam (Cruz, 2015).

Os participantes da pesquisa foram estudar na UFFS Campus Realeza/PR com origem dos Estados: Paraná majoritariamente (55,6\%), seguido por SP (18,3\%), SC (15,2\%), RS (7\%) e de outros Estados (3,9\%).

Sendo possível observar que a maioria ainda é do mesmo Estado e da região Sul, entretanto existem pessoas de outras regiões que a fim de ingressar em veterinária enfrentam grandes deslocamentos. A distribuição por categoria (fase do curso ou formado) e por sexo pode ser observada na Figura 1. 
Figura 1 - Número de participantes da pesquisa de acordo com o sexo e situação no curso de medicina veterinária da Universidade Federal da Fronteira Sul.

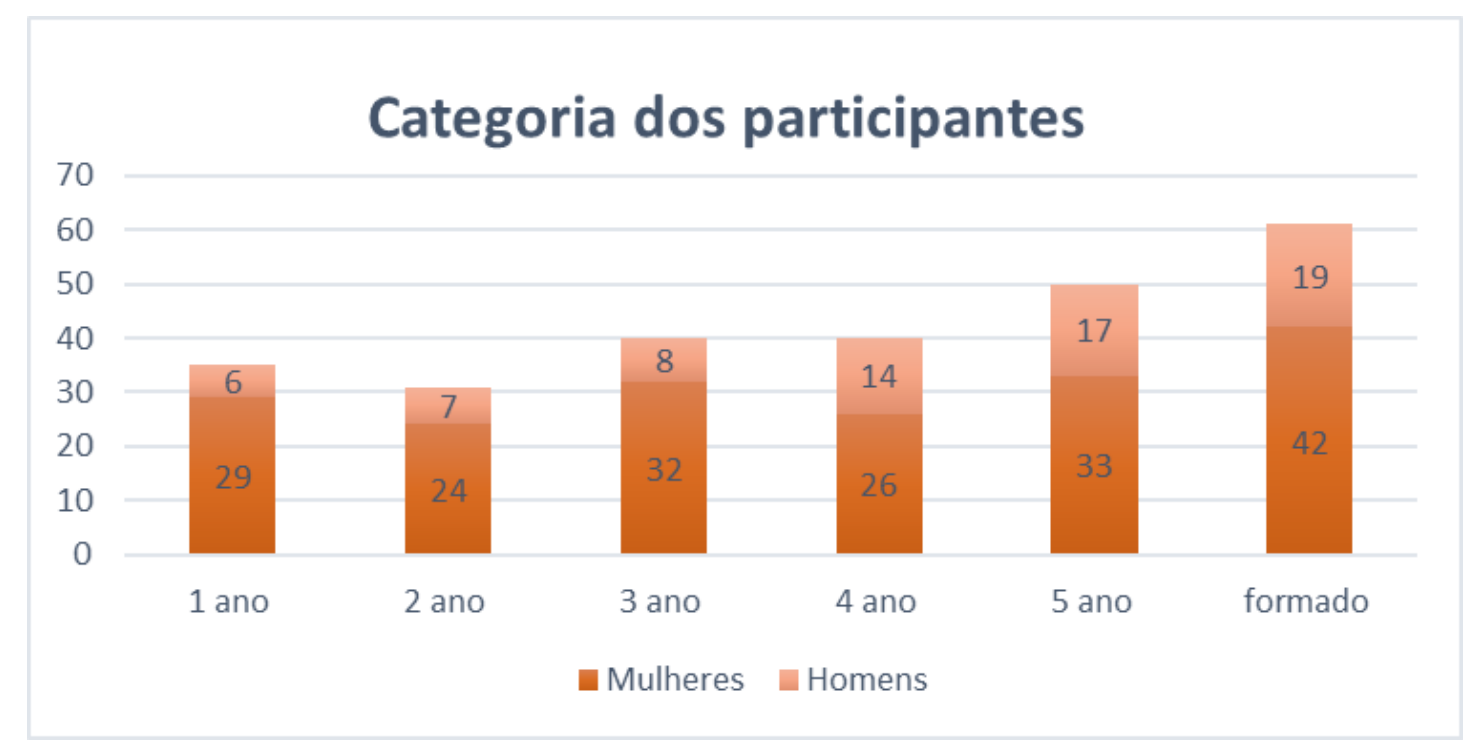

Fonte: Elaborada pelos autores (Ago/2020 a Abr/2021).

A maioria dos estudantes que participou desta pesquisa era do sexo feminino $(72,4 \%$; 186/257). Resultado também observado por Cruz (2015) e Teles et. al. (2017) no curso de medicina veterinária na região Sudeste (58,03\%; 1.888/3.253) e na Universidade Federal de Pelotas $(77,7 \%$; 178/229) respectivamente. Indicando que as mulheres estão conquistando cada vez mais um mercado antes visto como uma profissão predominantemente masculina (Cruz, 2015; Teles et al., 2017).

Até os anos 80, o número mulheres que realizavam novas inscrições nos Conselhos Federal e Regional de Medicina Veterinária - CFMV/CRMVs era abaixo de 20\%, a partir dos anos 2.000 houve uma ascensão e em 2015 passaram a representar 60\% das inscrições (Cruz, 2015; Teles et al., 2017). A tendência é que continuem aumentando essa porcentagem, como demonstram os resultados desta pesquisa.

Dos participantes da pesquisa, 5\% (13/257) já haviam concluído outra graduação e 8,9\% (23/257) não finalizaram a primeira graduação. Ainda, 33,8\% (87/257) haviam tentado outro curso, sendo que 44,8\% (39/87) na área da saúde, 34,5\% (30/87) na área das ciências biológicas ou agrárias e 20,7\% (18/87) outros cursos. Esses resultados indicam que a maioria estava convicta na escolha do curso (ou pelo menos na área). Além disso, 5\% dos estudantes que concluíram outra graduação afirmaram fazer o curso de medicina veterinária para complementar sua primeira graduação ou realizar o sonho de atuar na área que realmente gostam. No estudo realizado por Cruz (2015) os participantes que tentaram outro processo seletivo correspondem a 46,6\% (1.028/2.206) demonstrando como geralmente alunos mais novos possuem pouco conhecimento e uma maior indecisão em relação ao ingresso no ensino superior.

A maioria dos alunos que responderam esta pesquisa residiam exclusivamente em zona urbana $(68,5 \%$; 176/257) e haviam cursado o ensino médio regular (77,8\%; 200/257). De origem rural e mista (urbana e rural) foram respectivamente 26,1\% (67/257) e 5,4\% (14/257). E 22,2\% (57/257) haviam feito curso técnico antes de ingressar na graduação. Aqueles que tiveram maior contato com o campo ou fizeram ensino médio agrícola geralmente têm mais experiências diárias com a área, o que poderia influenciar na escolha da profissão. Assim também àqueles que viveram em propriedade rural, e que pretendem dar continuidade ao negócio familiar.

Apenas 8,9\% (23/257) dos participantes alegaram ter escolhido veterinária por influência da família ou por ser a opção mais viável no momento. Já 91,1\% (234/257) afirmaram que a escolha foi por afinidade e identificação com a área. Assim como no estudo de Cruz (2015) e Teles et. al. (2017), os participantes afirmaram ter escolhido esta profissão por 
admirar o trabalho e amor aos animais, sendo 71,12\% (2.911/4.093) e 72,5\% (156/215) respectivamente. Estas convicções sugerem que os jovens têm um sonho de cuidar dos animais, porém pouco domínio sobre o quão abrangente é a medicina veterinária. Direcionam sua escolha à terapêutica, esquecendo da questão profilática, não só animal como humana e ambiental.

Ao ingressar no curso de medicina veterinária a maioria dos alunos tinha como interesse trabalhar nas áreas de clínica ou cirurgia de pequenos e grandes animais $(35,4 \% ; 91 / 257$ e 28,8\%; 74/257 respectivamente), como pode ser observado na Figura 2.

Figura 2 - Número total e área de interesse dos participantes quando iniciaram a graduação e de acordo com a situação no curso de medicina veterinária.

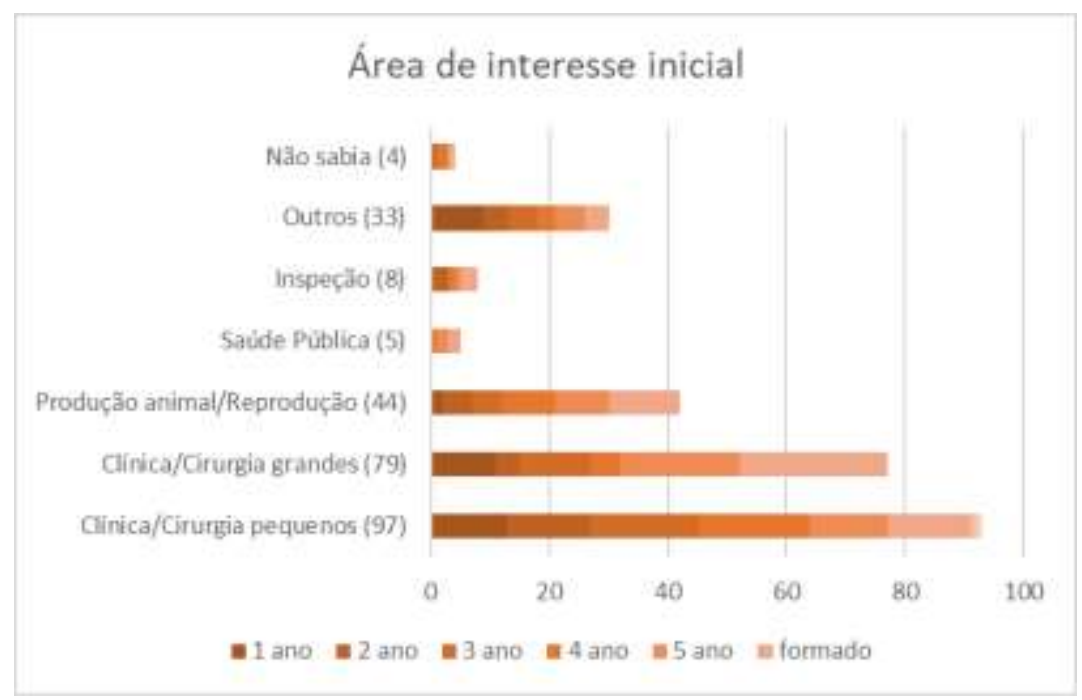

Fonte: Elaborada pelos autores (Ago/2020 a Abr/2021).

A medicina veterinária é mais conhecida como uma profissão clínica. E a clínica de pequenos animais está entre os ramos mais desejados, isso pode ser devido ao setor pet brasileiro ser o segundo maior do mundo (Freitas, 2016). Os animais de companhia que antes ficavam fora das casas, hoje estão dormindo com seus tutores e participando de suas rotinas, indo viajar, sendo membros integrantes das famílias. Essas mudanças tornaram o ramo ainda mais desejado, com aumento da demanda e do contato social com os animais. Cada vez mais as pessoas escolhem profissões de acordo com aquilo que têm contato e amam fazer (Freitas, 2016; Souza, 2018).

A área de interesse mudou para 45,1\% (116/257) dos participantes da pesquisa. Sendo que a partir do segundo ano de graduação o número de mudanças de opinião dobrou, como pode ser observado na Figura 3. 
Figura 3 - Número de participantes que mudaram de opinião em relação à área inicialmente escolhida, de acordo com sua situação no curso de medicina veterinária.

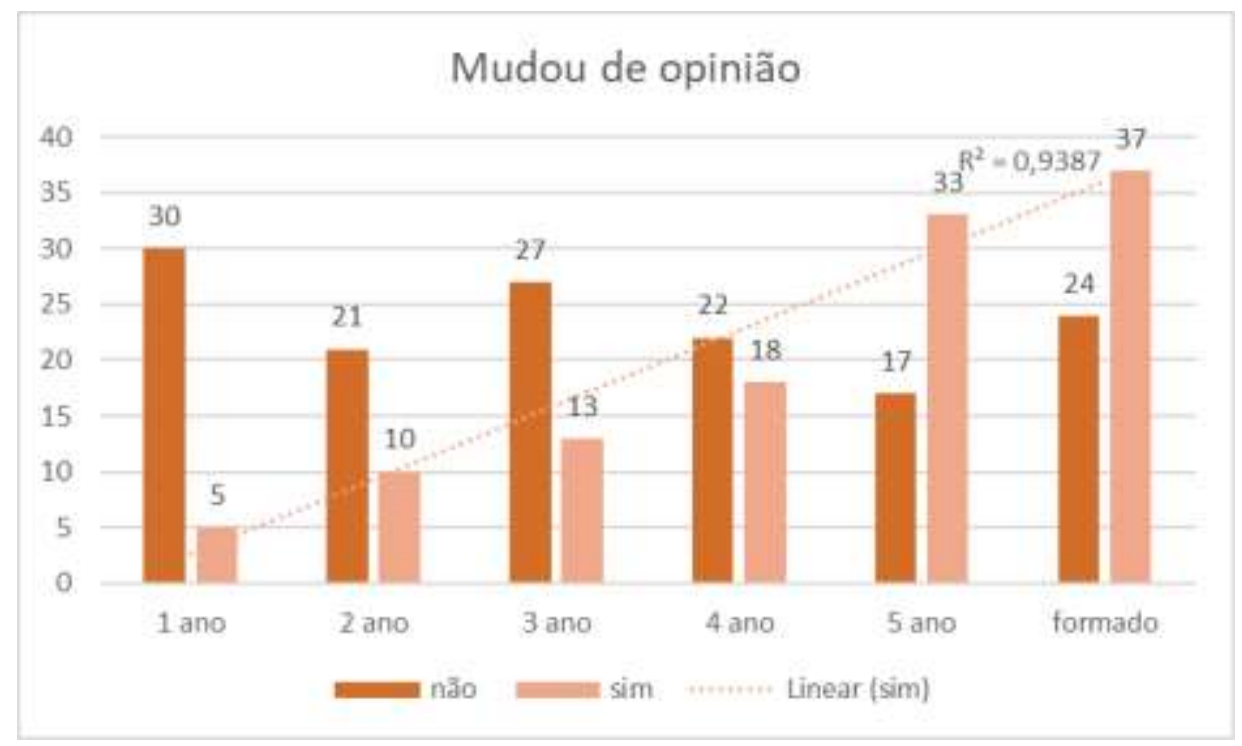

Fonte: Elaborada pelos autores (Ago/2020 a Abr/2021).

\subsection{Afinidade pela área de alimentos}

Apenas 3,1\% (8/257) dos participantes afirmaram não consumir produtos de origem animal. No Brasil, 98,5\% das residências consomem produtos de origem animal regularmente. Sendo que $80 \%$ da população consome de 2 a 3 vezes por semana carne de frango, além desta ser a carne mais consumida de forma igualitária entre as classes sociais (ABPA, 2021).

Ademais, os produtos não comestíveis de origem animal que são principalmente as vísceras, penas, pelos, sangue, gordura e ossos, são destinados para a fabricação de diversos produtos como farmacêuticos, fertilizantes, ração animal, indústria automobilística, indústrias de roupas e acessórios. Esses devem ser tratados com a mesma importância que os produtos comestíveis, pois quando não manipulados da forma correta, podem representar grande risco epidemiológico para a disseminação de enfermidades (Moreira, 2018).

Quando questionados, 73,9\% (190/257) dos alunos sabiam antes de cursar medicina veterinária que o profissional atua na área de alimentos, através da inspeção e vigilância higiênico-sanitária de frigoríficos, supermercados, laticínios e indústrias, enquanto 26,1\% (67/257) não sabiam. Os resultados demonstram que mais da metade dos estudantes afirmaram ter conhecimento sobre a área de atuação ao ingressar no curso. Contudo, a tendência para atuar nesta área tem seu crescimento linear com o decorrer das fases de ensino, de modo que os estudantes do início do curso não se apresentam tão adeptos como os das últimas fases para atuar na área de produtos de origem animal, como observado na Figura 4. Essa crescente mudança pode ser devido a aquisição de conhecimento e aproximação com as áreas de atuação, oferta de oportunidade, maior demanda de mercado. 
Figura 4 - Número de participantes que demonstraram interesse em trabalhar ou não na área de Produtos de Origem Animal (POA), de acordo com sua situação no curso de medicina veterinária.

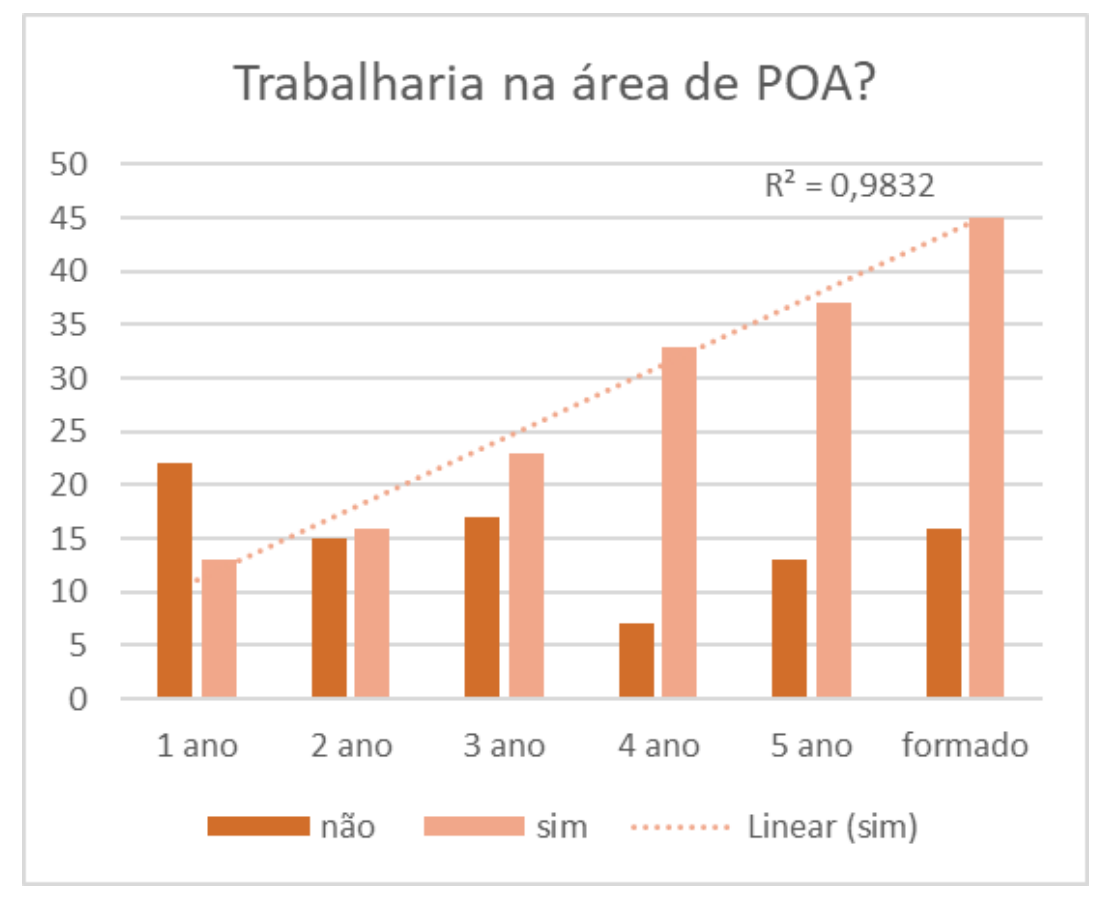

Fonte: Elaborada pelos autores (Ago/2020 a Abr/2021).

Para 34,6\% (89/257) dos participantes a área de alimentos é importante, mas responderam não ter afinidade, interesse e não se sentir confortável para atuar na área, os outros 65,4\% (168/257) afirmaram sentir interesse pela área e pela remuneração, reconhecendo sua importância, além de haver um desejo para conhecer mais sobre o campo de trabalho e contribuir com a comunidade.

Ao avaliar as áreas escolhidas pelos graduandos para realizar o estágio obrigatório e após verificar em quais áreas estão atuando, é possível perceber que nem sempre a área escolhida para atuar é a que apresenta empregos disponíveis, fazendo com que haja necessidade de adaptar as demandas. Como podemos observar na Figura 5.

Figura 5 - Áreas de atuação no estágio curricular obrigatório durante o curso de medicina veterinária e na vida profissional dos participantes da pesquisa.

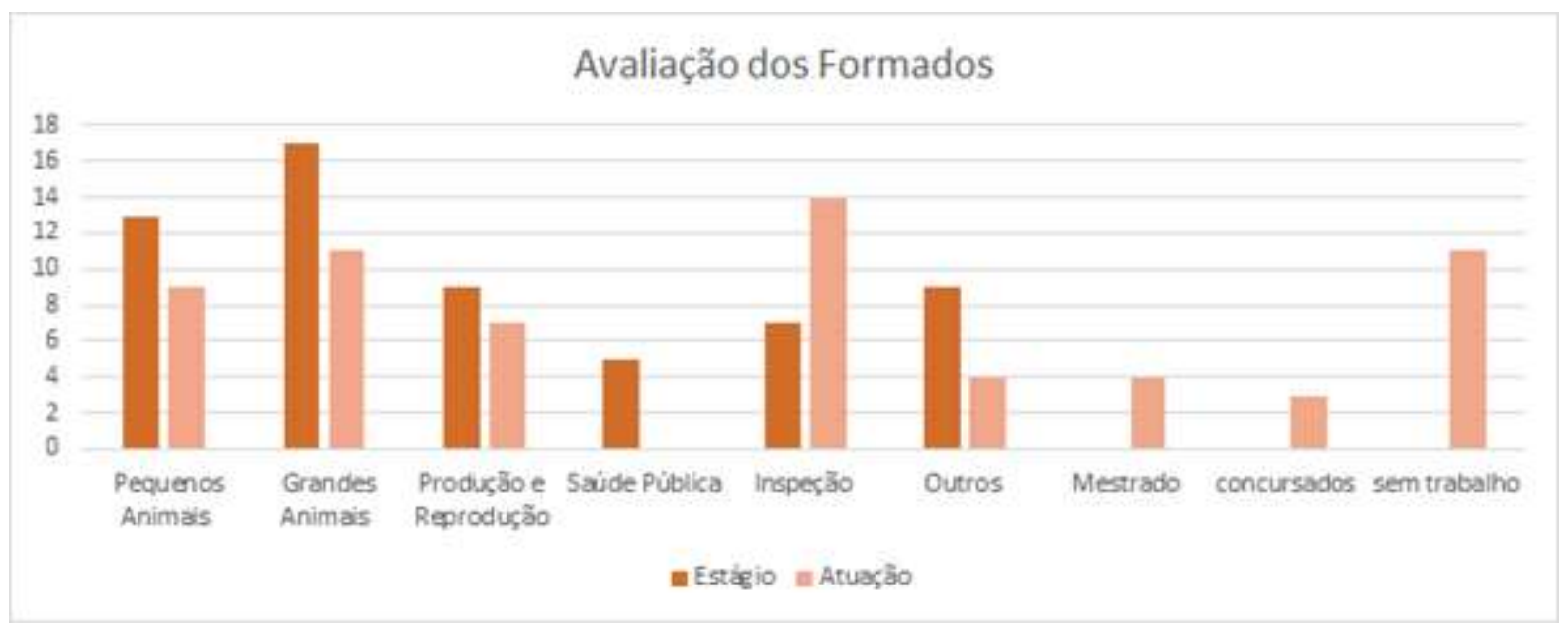

Fonte: Elaborada pelos autores (Ago/2020 a Abr/2021). 
O Brasil lidera os rankings mundiais de exportação das carnes de frango, bovinos e bubalinos, além de ser o quarto maior na exportação de suínos. Ademais os Estados do Sul são destaque na produção de produtos de origem animal: Santa Catarina é o maior exportador de suíno e carne de pato; Rio Grande do Sul é o maior exportador de carne de peru e segundo maior exportador de ovos; e o Paraná é o maior exportador de carne de frango e material genético avícola (ABPA, 2021).

\section{Conclusão}

A maioria dos alunos que ingressaram no curso de medicina veterinária da Universidade Federal da Fronteira Sul eram jovens entre 20 a 25 anos (60,31\% das respostas), sendo que no primeiro ano $60 \%$ eram menores de 20 anos. Muitos que saíram do ensino médio e ingressaram no ensino superior. Entre os participantes desta pesquisa a maioria eram de mulheres (72,4\%), que haviam escolhido inicialmente a área de clínica e cirurgia, seja de pequenos ou grandes animais $(64,2 \%)$ e afirmaram ter escolhido o curso por afinidade e identificação com a área (91,1\%). Entretanto com o decurso da graduação e com a participação em outras atividades e disciplinas, $45,1 \%$ participantes mudaram de opinião quanto a área que inicialmente haviam escolhido. Antes de cursar medicina veterinária 73,9\% dos participantes tinham o conhecimento que o profissional poderia atuar na área de alimentos, e 65,4\% afirmaram sentir interesse pela área, por reconhecer a importância e querer contribuir com a comunidade.

Assim, é essencial incentivar os alunos a realizar diversas atividades extracurriculares desde o início para que haja maior interação com o curso desde o ingresso nas mais diferentes áreas de atuação, resultando na ampliação das oportunidades. As fases iniciais mesmo tendo conhecimento sobre a possibilidade de atuação nas áreas de alimentos não tem tanta aceitabilidade quanto às últimas fases quando o aluno tem maior contato com a disciplina, melhor conhecimento sobre a demanda de mercado e sobre a necessidade de empregabilidade. Além disso, seria relevante no ensino médio haver maior ênfase para apresentar aos estudantes os cursos e suas áreas de atuação, assim estes teriam maior segurança e noção para fazerem suas escolhas.

Mais estudos são necessários para aprofundamento no currículo do curso, já que está em processo de modificação as novas diretrizes nacionais e inclusão da curricularização da extensão, na preparação dos alunos, com desenvolvimento de habilidades exigidas no mercado de trabalho, e nas questões voltadas a interação dos discentes com as diversas possibilidades de trabalho na área de alimentos.

\section{Referências}

Associação Brasileira de Proteína Animal [ABPA] (2021). Relatório Anual ABPA São Paulo. https://abpa-br.org/wpcontent/uploads/2021/04/ABPA_Relatorio_Anual_2021_web.pdf

Andrade Júnior, A. G. Piñeiro, M. B. C. Munareto, T. S. D. Capella, S. O. \& Nobre, M. O. (2019). A Medicina Veterinária e a formação dos profissionais na atualidade. In D. F. Andrade (Ed.), Educação no Século XXI: percepções (pp. 56-60). Poisson.

Associação das Indústrias Exportadoras de Carne [ABIEC] (2020). Beef REPORT - Perfil da Pecuária no Brasil. ABIEC: Brasília. https://www.cicarne.com.br/wp-content/uploads/2020/05/SUM\%c3\%81RIO-BEEF-REPORT-2020_NET.pdf

Decreto-lei n ${ }^{\circ}$ 5.517, de 23 de outubro de 1968. (1968). Dispões sobre o exercício da profissão de Médico Veterinário e cria os Conselhos Federal e Regionais de Medicina Veterinária. Brasília, DF. http://www.planalto.gov.br/ccivil_03/leis/15517.htm

Cobucci, G. C. (2017). Metodologias ativas e aspectos pedagógicos no ensino de graduação em Medicina Veterinária. [Dissertação Mestrado na Universidade Federal de Viçosa]. Repositório UFV https://www.locus.ufv.br/bitstream/123456789/17771/1/texto\%20completo.pdf

Companhia Nacional de Abastecimento [CONAB] (2019). Perspectivas para a Agropecuária. Brasília. https://www.conab.gov.br/perspectivas-para-aagropecuaria.

Costa, B. S., Ciríaco, N. M., Santos, W. L. M., Ornellas, C. B. D. Moreira dos Santos. T. (2015). História e evolução da inspeção industrial e sanitária de produtos de origem animal no Brasil. In N. R. S. Martins (Ed.), Cadernos Técnicos de Veterinária e Zootecnia: inspeção de produtos de origem animal (pp. 09-31). Fepmvz. 
Cruz, C. A. (2015). O ensino da saúde pública veterinária nos cursos de graduação em medicina veterinária da região sudeste do Brasil. [Dissertação de Mestrado, Faculdade de Ciências Agrárias e Veterinárias da Universidade Estadual Paulista]. Repositório UNESP https://repositorio.unesp.br/bitstream/handle/11449/126402/000837045.pdf?sequence=1\&isAllowed=y

Cardoso, A. C. M., Serra, A. C. C.,Carvalho, A. C., Silva, B. S., Souza Silva, R. (2019). Fatores que influenciam a escolha profissional: uma pesquisa com os estudantes do ensino médio integrado do IFSP. Scientia Vitae, 7(23), 42-49. http://www.revistaifspsr.com/v7n23p42-49.pdf

Freitas, F. J. S. (2016). Ensino de administração nos cursos de medicina veterinária e a visão dos profissionais sobre a gestão dos serviços veterinários para pequenos animais diante da expansão do mercado pet. [Tese de Doutoramento, Faculdade de Zootecnia e Engenharia de Alimentos da Universidade de São Paulo]. https://www.teses.usp.br/teses/disponiveis/74/74134/tde-16032017-095538/pt-br.php

Magioli, C. A. (2017). Considerações sobre possíveis irregularidades em produtos de origem animal. Vigilância Sanitária em Debate: Sociedade, Ciência \& Tecnologia, 5(4), 2-8. https://doi.org/10.22239/2317-269X.00972

Moreira, D. S. (2018). Caracterização do fluxo de subprodutos não comestíveis de origem animal no Estado do Maranhão no período de 2013 a 2016. [Dissertação Mestrado em Defesa Animal da Universidade Estadual Do Maranhão]. Repositório da UEMA http://repositorio.uema.br/handle/123456789/1159?mode=full

Pfuetzenreiter, M. R. \& Zylberstajn, A. (2008). Percepções de estudantes de medicina veterinária sobre a atuação na área da saúde: um estudo baseado na idéia de "estilo de pensamento" de Ludwik Fleck. Ciência \& Saúde Coletiva, 13, 2105-2114. https://doi.org/10.1590/S1413-81232008000900015

Souza, A. F. B. (2018). O mercado pet brasileiro: Uma análise de 2012 a 2017. [Trabalho de Conclusão de Curso, Centro Universitário Municipal de Franca]. Repositório na Uni-FACEF https://periodicos.unifacef.com.br/index.php/rede/article/view/1708

Svoboda,W. K. \& Javorouski, E. B. (2011). O papel e a importância do médico veterinário na saúde pública. CRMV-PR. https://www.crmvpr.org.br/artigosView/91_O-papel-e-a-importancia-do-Medico-Veterinario-na-Saude-Publica.html

Taffarel, A. (2014). Aspectos do papel do médico veterinário na Saúde Pública, o ensino curricular e o conceito de One Health: revisão de literatura e considerações. [Trabalho de Conclusão de Curso, Faculdade de Veterinária da Universidade Federal do Rio Grande do Sul]. Repositório da UFRGS https://lume.ufrgs.br/handle/10183/127673

Teles, A. J.,Lima, J. V., Veeck, N. I. D. A., Almeida, R. B., Guimarães, T. G., Girolometto, G., \& Schuch, L. F. D. (2017). Percepção dos estudantes de medicina veterinária sobre a formação e atuação em saúde pública no âmbito da universidade federal de pelotas - RS. Science And Animal Health, 5(2), 125137. https://periodicos.ufpel.edu.br/ojs2/index.php/veterinaria/article/view/10830

Torres, V. F. \& Chirelli, M. Q. (2019). Formação Docente na Medicina Veterinária: desafios e estratégias desvendados pela análise temática. CIAIQ2019, 1 , 681-690. https://proceedings.ciaiq.org/index.php/CIAIQ2019/article/view/2238

Universidade Federal da Fronteira Sul [UFFS] (2010). Projeto pedagógico do curso de graduação em medicina veterinária: bacharelado. Chapecó: SC. https://www.uffs.edu.br/atos-normativos/ppc/ccmvre/2010-0001

Pâmela Strapasson - 35\% de participação na elaboração do manuscrito.Sonia Mara Fontes dos Santos - 30\% de participação na elaboração do manuscrito. Karina Ramirez Starikoff - 35\% de participação na elaboração do manuscrito. 